\title{
Optimization of Microwave-Osmotic Pretreatment of Apples with Subsequent Air-Drying for Preparing High-Quality Dried Product
}

\author{
Elham Azarpazhooh and Hosahalli S. Ramaswamy \\ Department of Food Science and Agricultural Chemistry, McGill University, Macdonald Campus, 21,111 Lakeshore Road, \\ Sainte-Anne-de-Bellevue, QC, Canada H9X 3V9 \\ Correspondence should be addressed to Hosahalli S. Ramaswamy, hosahalli.ramaswamy@mcgill.ca
}

Received 24 March 2011; Accepted 28 March 2011

Academic Editor: M. C. E. Yagoub

Copyright (C 2011 E. Azarpazhooh and H. S. Ramaswamy. This is an open access article distributed under the Creative Commons Attribution License, which permits unrestricted use, distribution, and reproduction in any medium, provided the original work is properly cited.

\begin{abstract}
Prepared apple (Red Gala) cylinders were subjected to microwave-osmotic dehydration treatment under continuous flow medium spray (MWODS) conditions and then air-dried to a final 20\% moisture content. The dried samples were evaluated for color and textural properties, and rehydration capacity. The MWODS pretreatments were based on a central composite rotatable design and a response surface methodology using five levels of sucrose concentration, temperature, and contact time at a constant flow rate of $2800 \mathrm{~mL} / \mathrm{min}$. The air-drying was carried out at $60^{\circ} \mathrm{C}, 15 \pm 1 \%$ relative humidity, and $0.64 \pm 0.02 \mathrm{~m} / \mathrm{s}$ air velocity. The results were compared to untreated air-dried (AD) (worst-case scenario) and freeze-dried (FD) (best-case scenario) apples without the MWODS treatment. Color properties were affected regardless of the type of treatment. Conventional AD apples were darker in color, whereas MWODS-treated samples were lighter with higher $L^{*}$ and $b^{*}$ values, higher Hue and Chroma values but lower $a^{*}$ value and $\Delta E$. Further the color parameters of MWODS-treated samples were closer or equal to the FD apples. The texture properties were also affected by the osmotic variables with MWODS treatment resulting in softer and chewier products. The AD samples were hard, and FD apples were brittle.
\end{abstract}

\section{Introduction}

Food industry interest in enhancing quality and marketability of dried foods has been continuously increasing. Osmotic dehydration (OD) pretreatment has long been recognized to improve product quality and reduce energy consumption. Osmotic drying is only a pretreatment, and hence a second-stage drying such as air, freeze, and vacuum drying is necessary to complete the process. It has been shown that the quality of air-, freeze-, or vacuum-dried fruits and vegetables could be improved by an osmotic pretreatment [1]. Freeze-drying (FD) is considered to be the best for keeping the quality attributes, but it is expensive [1]. In an earlier study [2], it was shown that a microwaveosmotic dehydration (MWODS) pretreatment could be used to accelerate the moisture removal from the fruit. The pretreatment resulted in removal of almost $50 \%$ of the fruit moisture in a short 30 min treatment time [2]; however, the influence of the treatment on product quality was not reported. There have been several studies on the evaluation of color change during osmotic dehydration. Osmotic dehydration (OD) reduces the discoloration of fruits by enzymatic browning by limiting exposure of fruits to oxygen [2], and the sugar uptake increases the stability of pigments during further drying and subsequent storage period. Nonenzymatic browning occurs during conventional drying and is major cause of color degradation in apple fruit. $\mathrm{SO}_{2}$ is usually employed to prevent these browning reactions, but the $\mathrm{OD}$ pretreatment can eliminate this step. The long dehydration times in conventional air-drying also lead to poor-quality product due to caramelization, Maillard reactions, and ascorbic acid oxidation. The OD pretreatment reduces the second stage of drying time and hence reduces the extent of these reactions. 
TABLE 1: Experimental design of process in coded and actual variables and values of experimental data (color parameters).

\begin{tabular}{|c|c|c|c|c|c|c|c|c|c|}
\hline $\begin{array}{l}\text { Process } \\
\text { conditions }\end{array}$ & $\begin{array}{c}\text { Sucrose } \\
\text { concentration } \\
\left({ }^{\circ} \mathrm{B}\right)\end{array}$ & $\begin{array}{c}\text { Temperature } \\
\left({ }^{\circ} \mathrm{C}\right)\end{array}$ & $\begin{array}{l}\text { Contact time } \\
\quad(\min )\end{array}$ & $L^{*}$ value & $a^{*}$ value & $b^{*}$ value & $\Delta E$ & Hue angle & Chroma \\
\hline 1 & $40(-1)$ & $40(-1)$ & $15(-1)$ & $75.9 \pm 2.36$ & $9.32 \pm 1.09$ & $35 \pm 0.46$ & $13.3 \pm 0.8$ & $75.1 \pm 1.85$ & $36.2 \pm 0.2$ \\
\hline 2 & $60(+1)$ & $40(-1)$ & $15(-1)$ & $74.6 \pm 1.95$ & $9.19 \pm 0.06$ & $31 \pm 0.56$ & $12.9 \pm 1.2$ & $73.3 \pm 0.39$ & $32 \pm 0.5$ \\
\hline 3 & $40(-1)$ & $60(+\mathrm{l})$ & $15(-1)$ & $76.7 \pm 1.95$ & $7.82 \pm 1.59$ & $32 \pm 1.68$ & $10.7 \pm 0.3$ & $76.2 \pm 2$ & $32.8 \pm 2$ \\
\hline 4 & $60(+1)$ & $60(+1)$ & $15(-1)$ & $77.3 \pm 0.21$ & $7.88 \pm 0$ & $31 \pm 1.36$ & $10 \pm 0.4$ & $75.7 \pm 0.6$ & $32 \pm 1.3$ \\
\hline 5 & $40(-1)$ & $40(-1)$ & $45(+1)$ & $79.7 \pm 0.07$ & $7.58 \pm 0.6$ & $33 \pm 0.89$ & $8.8 \pm 0.1$ & $77 \pm 1.33$ & $33.8 \pm 0.7$ \\
\hline 6 & $60(+1)$ & $40(-1)$ & $45(+1)$ & $78 \pm 0.33$ & $7.13 \pm 0.68$ & $31 \pm 0.77$ & $9.1 \pm 0.7$ & $77 \pm 0.88$ & $31.8 \pm 0.9$ \\
\hline 7 & $40(-1)$ & $60(+1)$ & $45(+1)$ & $79.4 \pm 1.02$ & $6.56 \pm 0.34$ & $30 \pm 1.44$ & $7.4 \pm 1$ & $77.6 \pm 0.04$ & $30.6 \pm 1.5$ \\
\hline 8 & $60(+1)$ & $60(+1)$ & $45(+1)$ & $79.6 \pm 1.47$ & $6.3 \pm 0.8$ & $31 \pm 11.17$ & $7.4 \pm 4.1$ & $78.6 \pm 6.14$ & $32 \pm 11$ \\
\hline 9 & $33(-1.68)$ & $50(0)$ & $30(0)$ & $79.2 \pm 0485$ & $7.1 \pm 0.79$ & $32 \pm 1.38$ & $8.3 \pm 0.5$ & $77.3 \pm 0.83$ & $32.4 \pm L 5$ \\
\hline 10 & $67(+1.68)$ & $50(0)$ & $30(0)$ & $78.3 \pm 1.05$ & $6.78 \pm 1.22$ & $29 \pm 1.15$ & $8.3 \pm 0.1$ & $77 \pm 2.76$ & $30 \pm 0.8$ \\
\hline 11 & $50(0)$ & $33(-1.68)$ & $30(0)$ & $79.3 \pm 1.74$ & $8.93 \pm 1.62$ & $33 \pm 1.02$ & $10 \pm 0.3$ & $74.9 \pm 3.06$ & $34.3 \pm 0.6$ \\
\hline 12 & $50(0)$ & $67(+1.68)$ & $30(0)$ & $81.3 \pm 1.74$ & $6.96 \pm 0.74$ & $31 \pm 0.75$ & $6.5 \pm 0.1$ & $77.3 \pm 1.61$ & $31.6 \pm 0.6$ \\
\hline 13 & $50(0)$ & $50(0)$ & $5(-1.68)$ & $72 \pm 0.62$ & $9.1 \pm 0.75$ & $34 \pm 0.14$ & $15.7 \pm 0.7$ & $74.9 \pm 1.25$ & $34.9 \pm 0.1$ \\
\hline 14 & $50(0)$ & $50(0)$ & $55(+1.68)$ & $77.1 \pm 0.23$ & $6.31 \pm 0.16$ & $32 \pm 1.15$ & $9.8 \pm 0.5$ & $78.9 \pm 0.66$ & $32.9 \pm 1.1$ \\
\hline 15 & $50(0)$ & $50(0)$ & $30(0)$ & $81.4 \pm 0.10$ & $5.46 \pm 0.23$ & $33 \pm 0.79$ & $6.7 \pm 0.6$ & $80.6 \pm 0.17$ & $33.5 \pm 0.8$ \\
\hline 16 & $50(0)$ & $50(0)$ & $30(0)$ & $82.6 \pm 0.06$ & $4.35 \pm 0.99$ & $35 \pm 1.04$ & $6.8 \pm 0.6$ & $82.8 \pm 1.83$ & $34.8 \pm 0.9$ \\
\hline 17 & $50(0)$ & $50(0)$ & $30(0)$ & $81.3 \pm 0.10$ & $4.35 \pm 0.53$ & $33 \pm 0.76$ & $6 \pm 0.7$ & $82.4 \pm 0.74$ & $33 \pm 0.8$ \\
\hline 18 & $50(0)$ & $50(0)$ & $30(0)$ & $81 \pm 1.09$ & $6.49 \pm 0.4$ & $33 \pm 0.99$ & $7.3 \pm 1.2$ & $78.8 \pm 0.34$ & $33.5 \pm 1$ \\
\hline 19 & $50(0)$ & $50(0)$ & $30(0)$ & $83.6 \pm 0.52$ & $6.47 \pm 0.15$ & $33 \pm 0.96$ & $5.9 \pm 0.4$ & $78.7 \pm 0.58$ & $33.1 \pm 0.9$ \\
\hline 20 & $50(0)$ & $50(0)$ & $30(0)$ & $82 \pm 0.76$ & $5.98 \pm 0.75$ & $34 \pm 1.44$ & $7.4 \pm 0.9$ & $80.1 \pm 1.63$ & $34.7 \pm 1.3$ \\
\hline
\end{tabular}

\pm are the standard deviations.

Falade et al. [3] reported that the transparency and color of the fruit may be favorably modified by the OD treatment. Falade and Igbeka [4] evaluated $L^{*}, a^{*}$, and $b^{*}$ values, color intensity, and chroma values of OD-treated and ovendried watermelon and reported that color parameters were improved with an increase in osmotic solution concentration. They reported that osmotic dehydration improves fruit quality by stabilizing color parameters and inhibiting decolourisation of fruit by enzymatic oxidative browning due to infusion of sugars. In addition, reducing the water activity of samples also decreases the nonenzymatic browning reaction [5].

Another important quality characteristic of dried products is texture, which is usually measured by mechanical tests. Puncture force is usually used to measure the textural propriety of most fresh products. Hardness of the product which is the force required to break the product is a commonly used texture parameter which has been correlated with the case hardening during drying [6]. Cell turgor is the main factor that contributes to mechanical properties of plant tissue. During osmotic treatment, changes that affect mechanical behavior of plant tissues are loss of cell turgidity and alteration of middle lamella [7]. Contreras et al. (2007) [8] reported that soluble pectin is increased during drying which alters the cell bonding zone resulting in changing the solid matrix consistency. Osmotic dehydrated product has a softer texture due to leaching of calcium into the osmotic solution which in turn results in lowering the concentration of calcium content and hence the texture forming ability of the tissue [9]. In addition, rehydration capacity is used as an index of irreversible structural modification to the product texture during drying [10]. Most dehydrated products are frequently rehydrated, and it is desirable that during the rehydration the dried product absorbs the amount of moisture it lost during dehydration (rehydration ratio of 1.0). Compositional and structural changes during osmotic dehydration may have a negative impact on rehydration capacity [11].

The objectives of this study are (1) to study the effect of osmotic drying variables like sucrose concentration, temperature, and contact time on quality parameters (color, texture, and rehydration capacity) during the combination microwave-osmotic dehydration of apples under continuous flow medium spray conditions (MWODS) followed by a second-stage air-drying (to complete the drying process) using a central composite rotatable design (CCRD) of experiments and a response surface methodology (RSM) for data analysis and then comparing the results with conventionally air-dried $(\mathrm{AD})$ and freeze-dried (FD) apples without the MWODS treatment; (2) to find out optimization solutions for producing high-quality MWODS-air-dried apples.

\section{Materials and Methods}

2.1. Materials. Apples (Red Gala) were obtained from a local source and stored in a refrigerator at $2-5^{\circ} \mathrm{C}$ and $95 \%$ relative humidity until use ( 2 to 3 days). Commercial sucrose 
TABLE 2: Experimental design of process in coded and actual variables and values of experimental data (texture parameters, rehydration capacity).

\begin{tabular}{|c|c|c|c|c|c|c|c|}
\hline $\begin{array}{l}\text { Process } \\
\text { conditions }\end{array}$ & $\begin{array}{c}\text { Sucrose } \\
\text { concentration } \\
\left({ }^{\circ} \mathrm{B}\right)\end{array}$ & $\begin{array}{c}\text { Temperature } \\
\left({ }^{\circ} \mathrm{C}\right)\end{array}$ & $\begin{array}{l}\text { Contact time } \\
\quad(\min )\end{array}$ & Hardness (N) & $\begin{array}{l}\text { Rigidity } \\
(\mathrm{N} / \mathrm{mm})\end{array}$ & Energy $(\mathrm{J})$ & $\begin{array}{l}\text { Rehydration } \\
\text { capacity (\%) }\end{array}$ \\
\hline 1 & $40(-1)$ & $40(-1)$ & $15(-1)$ & $25.3 \pm 1.15$ & $25.7 \pm 1.09$ & $30.10 \pm 1.13$ & $98.3 \pm 1.07$ \\
\hline 2 & $60(+1)$ & $40(-1)$ & $15(-1)$ & $19.5 \pm 0.77$ & $21.8 \pm 0.85$ & $39.50 \pm 1.94$ & $94.6 \pm 1.39$ \\
\hline 3 & $40(-1)$ & $60(+1)$ & $15(-1)$ & $22.5 \pm 1.26$ & $49.8 \pm 2.21$ & $10.80 \pm 1.54$ & $97.8 \pm 1.4$ \\
\hline 4 & $60(+1)$ & $60(+1)$ & $15(-1)$ & $27.3 \pm 3.75$ & $43.9 \pm 1.29$ & $62.60 \pm 3.3$ & $94.9 \pm 1.34$ \\
\hline 5 & $40(-1)$ & $40(-1)$ & $45(+1)$ & $24.5 \pm 4.43$ & $29.4 \pm 0.78$ & $30.70 \pm 0.53$ & $67.4 \pm 1.27$ \\
\hline 6 & $60(+1)$ & $40(-1)$ & $45(+1)$ & $19.5 \pm 3.36$ & $48.2 \pm 0.01$ & $8.70 \pm 1.14$ & $64.8 \pm 1.34$ \\
\hline 7 & $40(-1)$ & $60(+1)$ & $45(+1)$ & $23.4 \pm 4.12$ & $14.3 \pm 1.36$ & $29.70 \pm 1.06$ & $77.4 \pm 2.17$ \\
\hline 8 & $60(+1)$ & $60(+1)$ & $45(+1)$ & $29 \pm 0.34$ & $31.1 \pm 0.44$ & $50.30 \pm 0.9$ & $75.6 \pm 1.29$ \\
\hline 9 & $33(-1.68)$ & $50(0)$ & $30(0)$ & $30 \pm 0.15$ & $22.2 \pm 2.11$ & $29.90 \pm 1.44$ & $70.9 \pm 0.67$ \\
\hline 10 & $67(+1.68)$ & $50(0)$ & $30(0)$ & $29.8 \pm 1.68$ & $33.1 \pm 0.42$ & $55.00 \pm 0.34$ & $66.3 \pm 0.84$ \\
\hline 11 & $50(0)$ & $33(-1.68)$ & $30(0)$ & $13.8 \pm 1.74$ & $27.4 \pm 0.88$ & $13.60 \pm 0.96$ & $78.6 \pm 1.37$ \\
\hline 12 & $50(0)$ & $67(+1.68)$ & $30(0)$ & $19.4 \pm 1.19$ & $33.2 \pm 0.59$ & $32.30 \pm 1.05$ & $87.2 \pm 0.8$ \\
\hline 13 & $50(0)$ & $50(0)$ & $5(-1.68)$ & $21.3 \pm 1.15$ & $40.2 \pm 1$ & $32.80 \pm 0.92$ & $122.3 \pm 10.3$ \\
\hline 14 & $50(0)$ & $50(0)$ & $55(+1.68)$ & $22.1 \pm 0.41$ & $32.6 \pm 0.94$ & $22.90 \pm 1.67$ & $80.1 \pm 0.87$ \\
\hline 15 & $50(0)$ & $50(0)$ & $30(0)$ & $8.79 \pm 1.23$ & $4.36 \pm 0.53$ & $4.89 \pm 1.33$ & $90.4 \pm 1.17$ \\
\hline 16 & $50(0)$ & $50(0)$ & $30(0)$ & $6.89 \pm 1.25$ & $4.57 \pm 0.75$ & $5.45 \pm 1.01$ & $91.2 \pm 1.07$ \\
\hline 17 & $50(0)$ & $50(0)$ & $30(0)$ & $3.3 \pm 1.26$ & $6.66 \pm 1.23$ & $3.98 \pm 0.91$ & $90.6 \pm 1.27$ \\
\hline 18 & $50(0)$ & $50(0)$ & $30(0)$ & $6.78 \pm 75.56$ & $7.51 \pm 1.13$ & $4.66 \pm 0.98$ & $89.9 \pm 1.45$ \\
\hline 19 & $50(0)$ & $50(0)$ & $30(0)$ & $5.89 \pm 0.25$ & $6.89 \pm 0.66$ & $5.18 \pm 0.95$ & $90.5 \pm 1.18$ \\
\hline 20 & $50(0)$ & $50(0)$ & $30(0)$ & $6.56 \pm 0.1$ & $5.84 \pm 1.28$ & $6.89 \pm 0.34$ & $91 \pm 0.55$ \\
\hline
\end{tabular}

\pm are the standard deviations.

(Redpath Canada Ltd., Montreal, QC) was used as the osmotic agent. Apples tissue was cut into small cylinders (14 mm height $\times 14 \mathrm{~mm}$ diameter) with a cork borer and a knife. The measured average moisture content of the prepared apple cylinders was $86 \%$ on a wet basis.

2.2. Osmotic Dehydration and Drying Procedure. The osmotic dehydration was carried out using a microwaveosmotic dehydration setup under continuous flow medium spray (MWODS) conditions based on a previous design [2]. Apple cylinders were weighed and placed into an MW transparent glass chamber inside a domestic microwave oven and sucrose solution at a selected concentration (33.3$\left.66.8^{\circ} \mathrm{B}\right)$ and temperature $\left(33.3-66.8^{\circ} \mathrm{C}\right)$ was sprayed on the samples for different contact times $(5-55 \mathrm{~min})$. For each experiment, the ratio of solution/sample was kept higher than $30: 1$ (w/w), and a flow rate of $2800 \mathrm{~mL} / \mathrm{min}$ was maintained using a peristaltic pump.

2.3. Air-Drying Method. Air-drying was done in a specially designed domestic oven (Equi-Flow Food Dehydrator, Marysville, WA) at $60^{\circ} \mathrm{C}$, flow rate of $0.64 \pm 0.02 \mathrm{~m} / \mathrm{s}$, and relative humidity of $15 \pm 1 \%$ as described by Nsonzi and Ramaswamy [12]. After MWODS pretreatment, the samples were taken out from the microwave, drained, and blotted with absorbent paper to remove the excess solution. These pretreated test samples were then subjected to air-drying until reaching a moisture content of $20 \%$ (wb). In order to determine the endpoint, the weight of test samples during drying was continuously monitored by attaching the drying tray to an electronic balance. After drying, products were cooled and packed in low-density polyethylene bags for measuring product quality attributes. Test samples without MWODS treatment also were similarly dried to get conventional air-dried (AD) samples.

2.4. Freeze-Drying. Freeze-drying (FD) was used as the best scenario for comparing the quality parameters of MWODSair-dried samples. $100 \mathrm{~g}$ of apple samples were placed in a freeze-dryer (Thermo Savant, MODULYOD-115, Holbrook, NY, USA) at a temperature of $-45^{\circ} \mathrm{C}$ and a vacuum of 100 120 mbar and dried for 20-24h.

2.5. Color Measurement. The color of apple test samples was evaluated in $L^{*}, a^{*}$, and $b^{*}$ units using a tristimulus Minolta Chroma Meter (Minolta Corp., Ramsey, NJ). The instrument was warmed up $20 \mathrm{~min}$ before experiments and calibrated with a white standard. At least six measurements were individually made, and the average value was reported. The color value was determined in a three-dimensional color space, $L^{*}$ (luminosity), $a^{*}$ (green - to red + ), and $b^{*}$ (blue - to yellow + ) values of the apple samples.

In addition, the total color difference, $\Delta E$ (1), Chroma (2), and Hue angle (3) were computed from the $L^{*}, a^{*}$, and $b^{*}$ values. Fresh apples were used as the reference for 


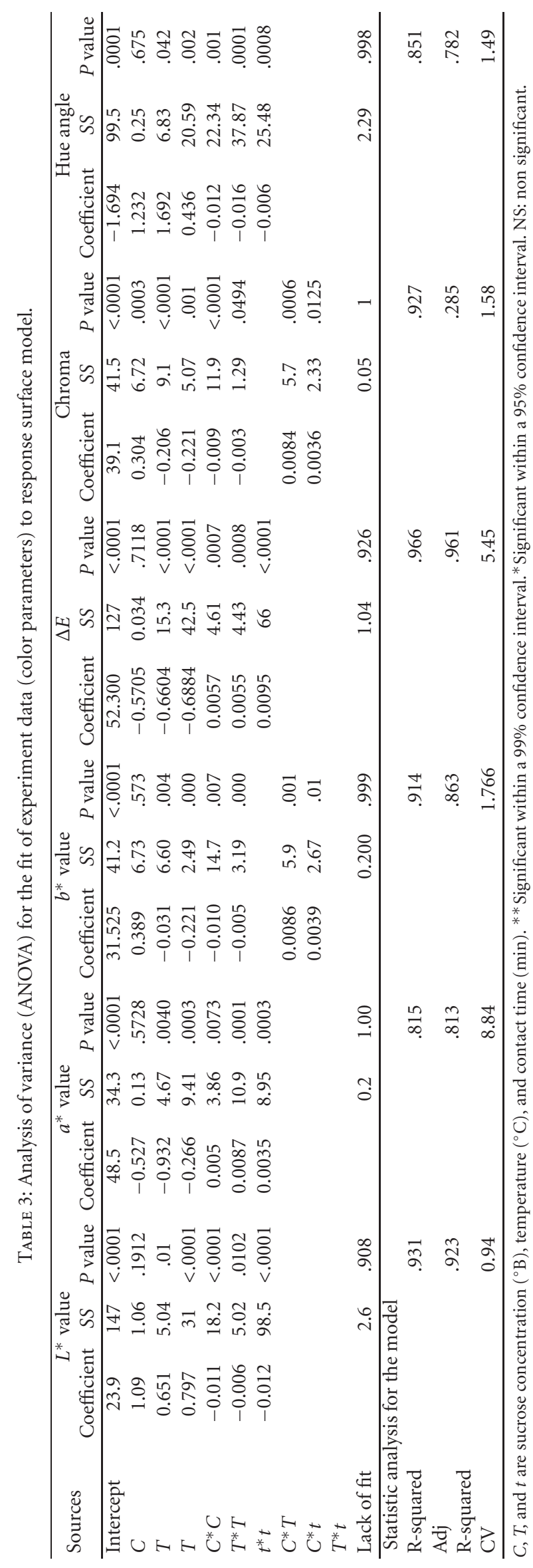




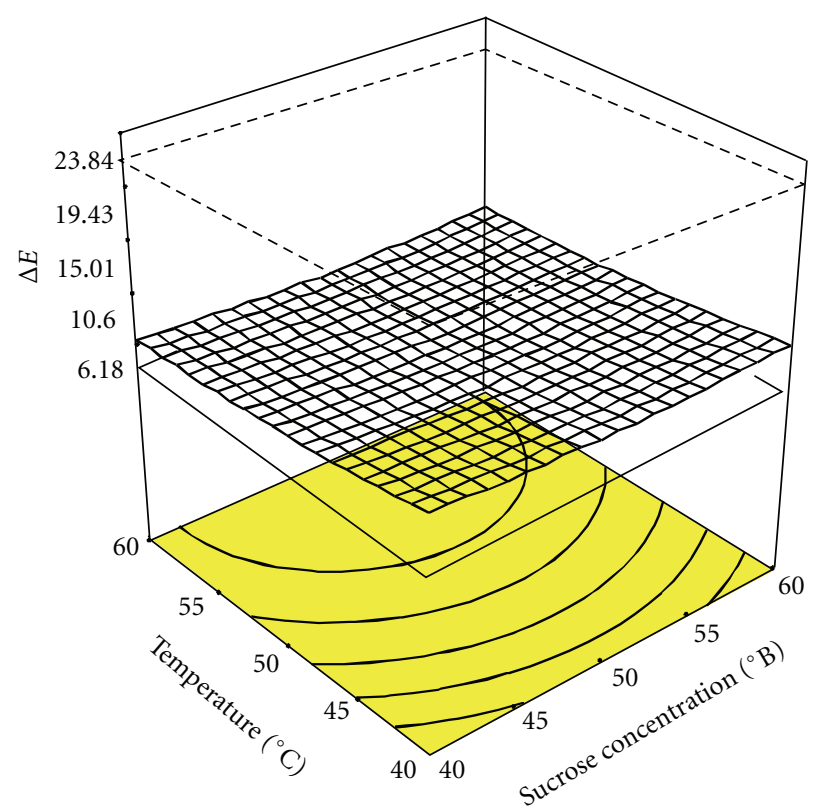

(a)

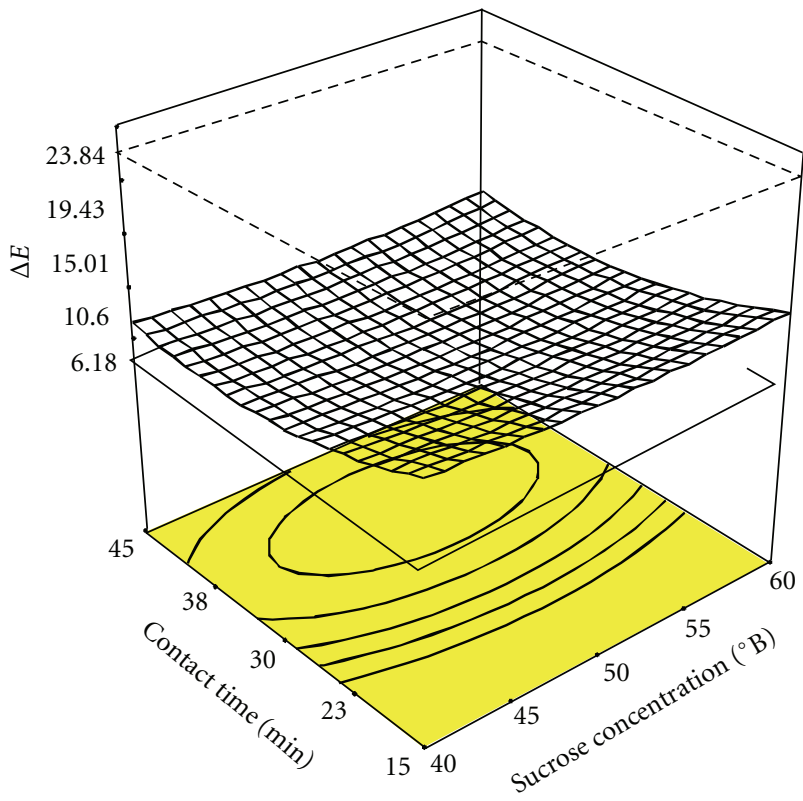

(b)

FIgURE 1: Response surface curves for total color difference $(\Delta E)$ : (a) effect of sucrose concentration and temperature at contact time 3 min; (b) effect of sucrose concentration and contact time at temperature $30^{\circ} \mathrm{C}$. The dashed square line is for air-dried sample $(\Delta E=22.84)$, and the solid square line is for the freeze-dried sample $(\Delta E=6.64)$.

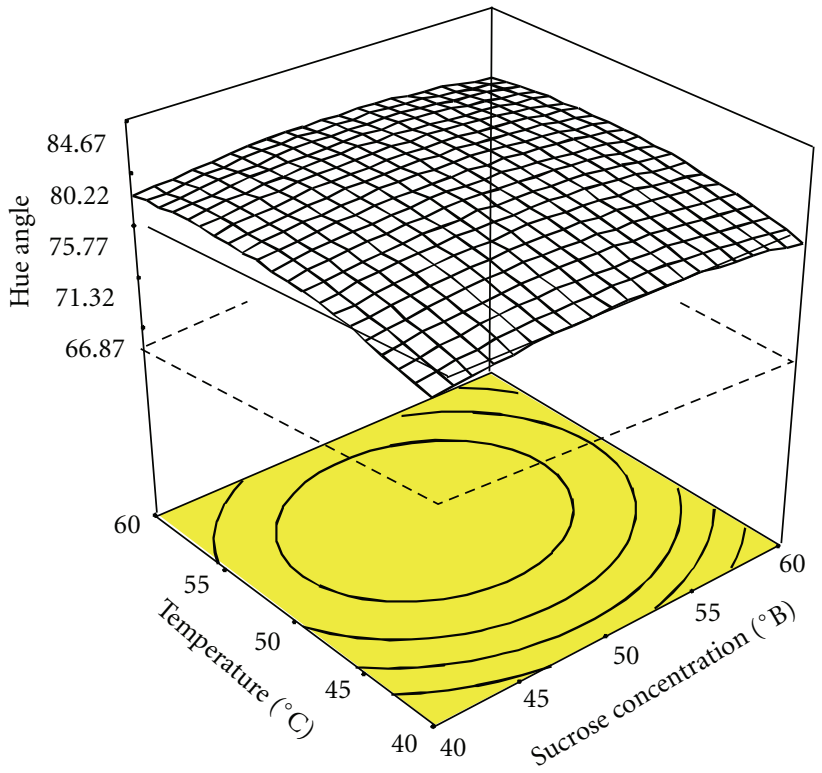

(a)

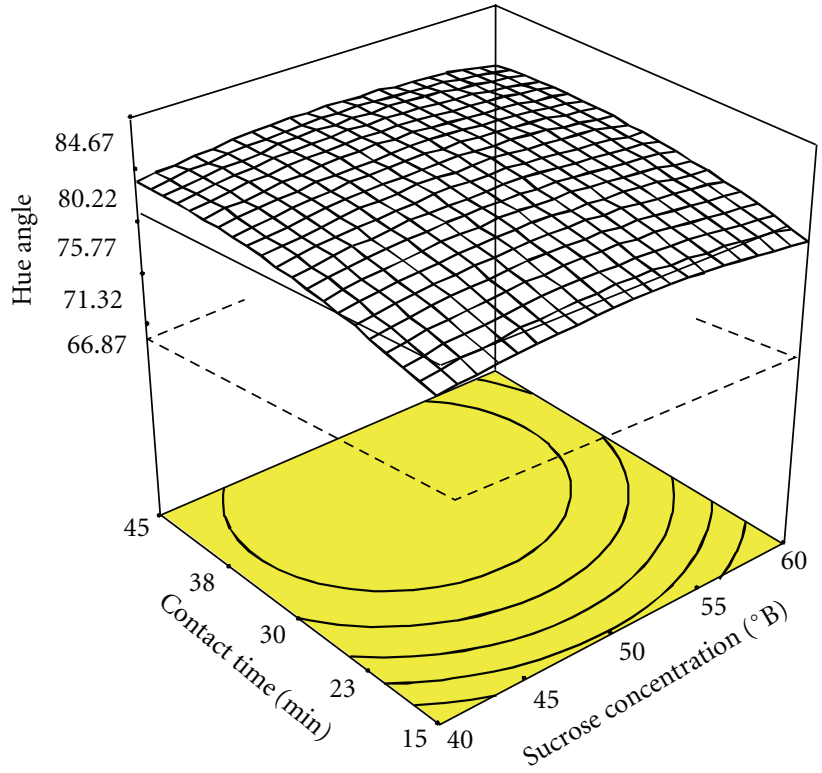

(b)

FIGURE 2: Response surface curves for Hue angle: (a) effect of sucrose concentration and temperature at contact time 30 min; (b) effect of sucrose concentration and contact time at temperature $30^{\circ} \mathrm{C}$. The dashed square line is for air-dried sample (Hue angle $\left.=66.9\right)$, and the solid square line is for the freeze-dried sample (Hue angle $=78.4$ ).

measuring $\Delta E$, where the subscript " 0 " refers to the color reading of fresh apples [13]:

$$
\begin{gathered}
\Delta E=\sqrt{\left(L_{0}^{*}-L^{*}\right)^{2}+\left(a_{0} *-a^{*}\right)^{2}+\left(b_{0}^{*}-b^{*}\right)^{2}}, \\
\text { Chroma }=\sqrt{\left(a^{*}+b *^{2}\right)},
\end{gathered}
$$

$$
\text { Hue angle }=\tan ^{-1}\left(\frac{b^{*}}{a^{*}}\right)
$$

2.6. Mechanical Properties Measurement. Mechanical properties of test samples were evaluated using a texture analyzer (TA/XT/PLUS Stable Micro. Systems Ltd., Godalming, UK) by means of a puncture test (2.5 diameter punch), 


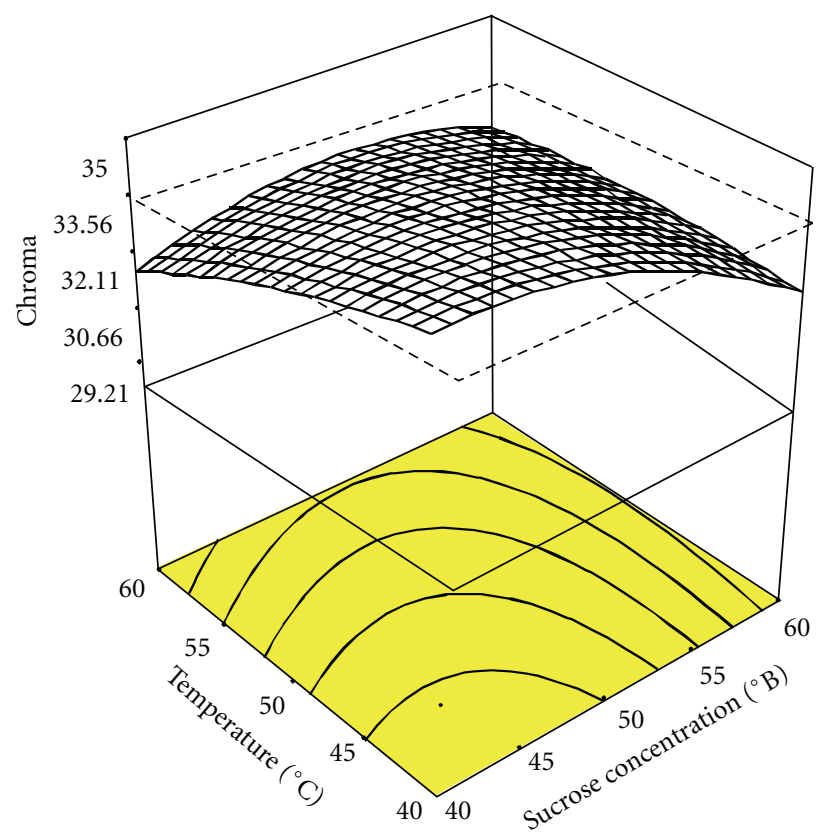

(a)

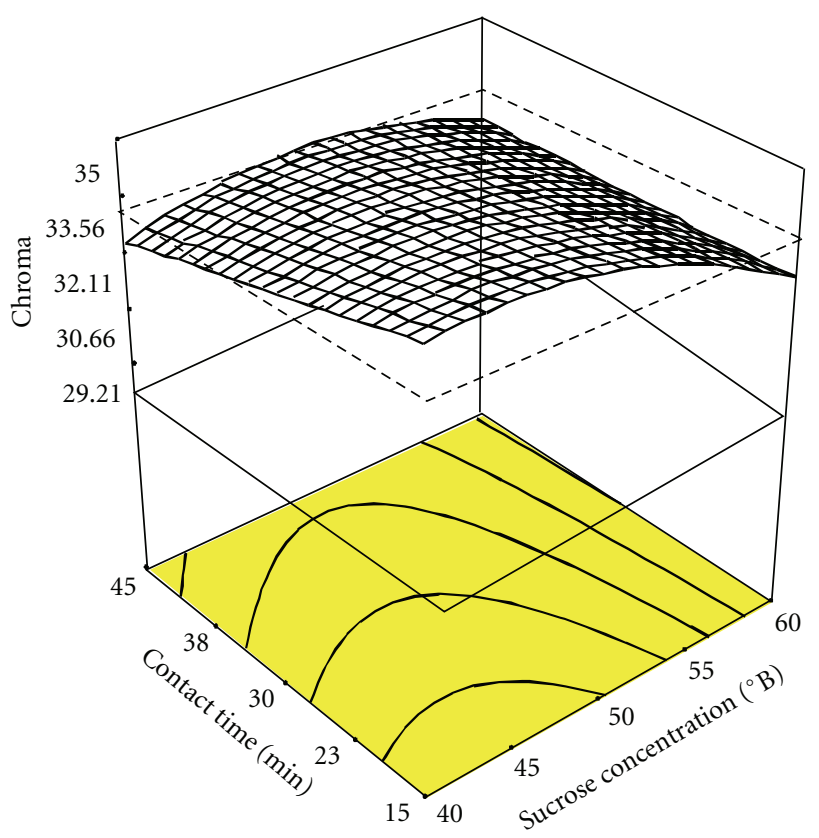

(b)

Figure 3: Response surface curves for Chroma: (a) effect of sucrose concentration and temperature at contact time 30 min; (b) effect of sucrose concentration and contact time at temperature $30^{\circ} \mathrm{C}$. The dashed square line is for air-dried sample $($ Chroma $=34.0)$, and the solid square line is for the freeze-dried sample (Chroma $=29.2)$.

considering a relative deformation of $85 \%$ at a deformation rate of $2 \mathrm{~mm} / \mathrm{s}$. Eight replicates were performed for each treatment, and the average was reported. A force-distance curve was recorded by the instrument, and three textural attributes including hardness $(\mathrm{N})$, the slope of the final section of the force-distance curve (rigidity) $(\mathrm{N} / \mathrm{mm})$, and the absorbed energy as area under the force-distance curve (J) were computed.

2.7. Rehydration Capacity. Apple cylinders after air-drying (conventional and MWODS treated) and freeze-drying were rehydrated by immersion in excess distilled water at room temperature $\left(20^{\circ} \mathrm{C}\right.$ for $\left.14 \mathrm{~h}\right)$. After rehydration, samples were placed in filter paper with a slight vacuum for $1 \mathrm{~min}$, and then their weights were measured. The rehydration capacity was determined as the weight ratio between the rehydrated sample and the sample before rehydration (g) [14]:

$$
\text { Rehydration Capacity }=\frac{W_{r}-W_{d}}{W_{d}},
$$

$W_{r}$ is the weight after rehydration $(\mathrm{kg})$, and $W_{d}$ is the weight of dried material $(\mathrm{kg})$. Experiments were carried out in triplicate, and the results were compared with $\mathrm{AD}$ and $\mathrm{FD}$ apples.

2.8. Experimental Design. Aiming to evaluate the influence of osmotic process variables on color, texture, and rehydration properties of dried apples, experiments were carried out according to a central composite rotatable design (CCRD) including 20 experiments formed by 8 factorial nodal points, 6 central points, and $6(\lambda=1.68)$ axial points (Tables 1 and
$2)$. The process variables were sucrose concentration (33.3$\left.66.8^{\circ} \mathrm{B}\right)$, solution temperature $\left(33.3-66.8^{\circ} \mathrm{C}\right)$, and contact (treatment) time (5-55 min) with a constant medium flow rate of $2800 \mathrm{~mL} / \mathrm{min}$. The Design Expert (Stat-Ease Inc., Version 6.01, Minneapolis, MN) software was used for data analysis. The following polynomial model was fitted to the data:

$$
\begin{aligned}
Y= & b_{0}+b_{1} x_{1}+b_{2} x_{2}+b_{3} x_{3}+b_{11} x_{1}^{2}+b_{22} x_{2}^{2}+b_{33} x_{3}^{2} \\
& +b_{12} x_{1} x_{2}+b_{13} x_{1} x_{3}+b_{23} x_{2} x_{3} .
\end{aligned}
$$

Here $b_{0}$ is the constant regression coefficients of the model; $Y$ represents the experimental response color or texture parameters or rehydration capacity; $x_{1}, x_{2}$, and $x_{3}$ in (5) are sucrose concentration $\left({ }^{\circ} \mathrm{B}\right)$, process temperature $\left({ }^{\circ} \mathrm{C}\right)$, and contact time, respectively. Analysis of variance (ANOVA) was used for testing the significant terms in the model, checking the adequacy of the model, and generating the various statistical parameters such as the coefficient of determination $\left(R^{2}\right)$, adjusted- $R^{2}$, and coefficient variance (CV) [15]. Response surface plots were also generated with the same software. The relationship between independent and dependent variables was illustrated in three-dimensional representations of the response. The response surfaces were based on the coefficients presented in Tables 3 and 4 . The multiple responses were simultaneously optimized by the desirability function method of the Design Expert software. For each variable and response, the desired goal was considered (maximized, minimized) and the independent variables were kept within range. 


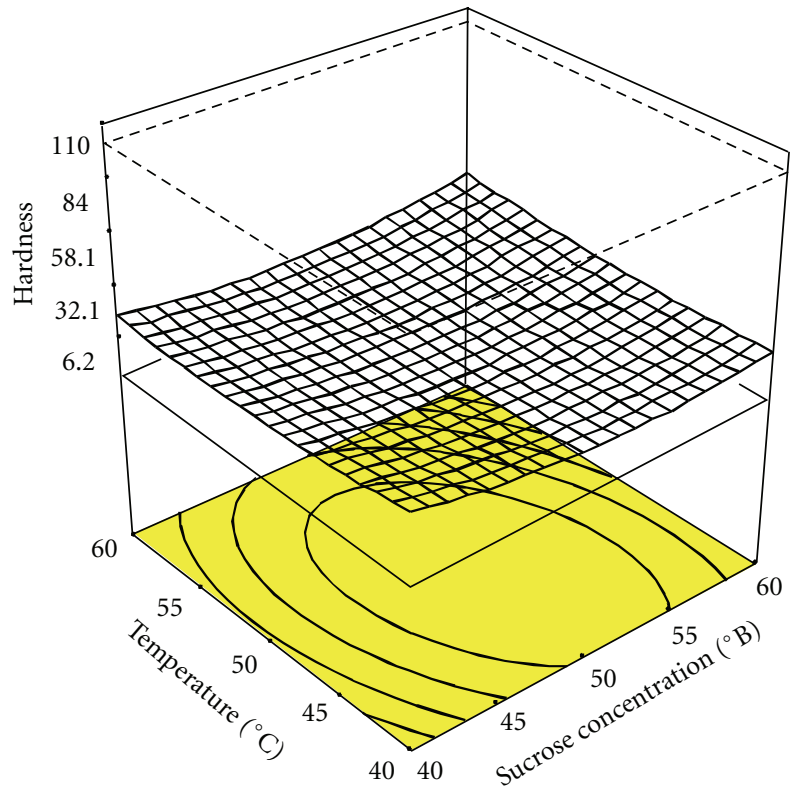

(a)

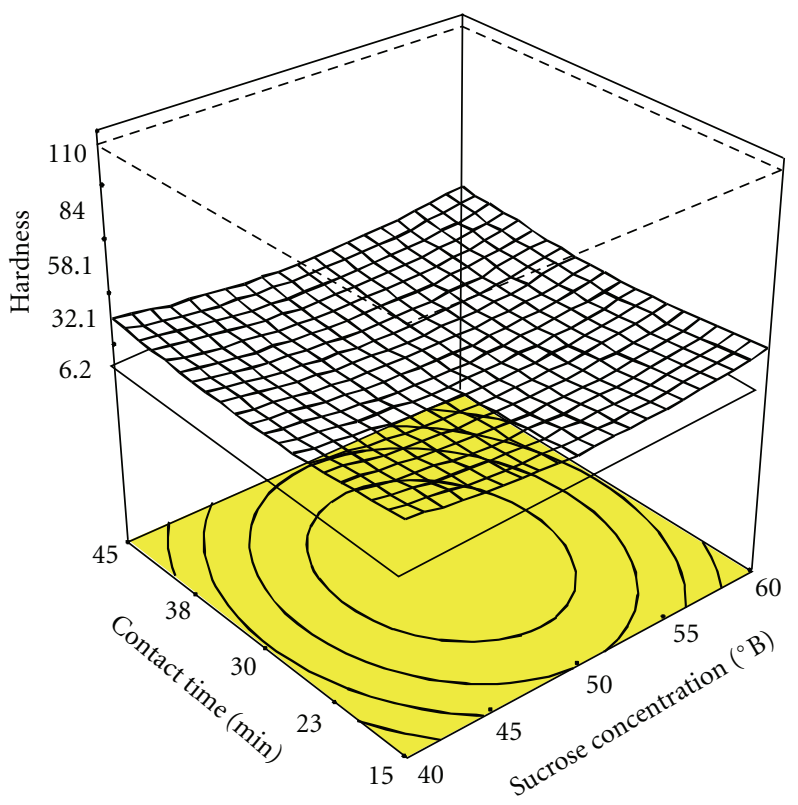

(b)

FIGURE 4: Response surface curves for hardness (N): (a) effect of sucrose concentration and temperature at contact time 30 min; (b) effect of sucrose concentration and contact time at temperature $30^{\circ} \mathrm{C}$. The dashed square line is for air-dried sample (hardness $\left.=110 \mathrm{~N}\right)$, and the solid square line is for the freeze-dried sample (hardness $=6.2 \mathrm{~N}$ ).

TABLE 4: Analysis of variance (ANOVA) for the fit of experiment data (texture parameters, rehydration capacity) to response surface model.

\begin{tabular}{|c|c|c|c|c|c|c|c|c|c|c|c|c|}
\hline \multirow{2}{*}{ Sources } & \multicolumn{3}{|c|}{ Hardness $(\mathrm{N})$} & \multicolumn{3}{|c|}{ Rigidity $(\mathrm{N} / \mathrm{mm})$} & \multicolumn{3}{|c|}{ Energy $(\mathrm{J})$} & \multicolumn{3}{|c|}{ Rehydration capacity } \\
\hline & Coefficient & SS & $P$ value & Coefficient & SS & $P$ value & Coefficient & SS & $P$ value & Coefficient & SS & $P$ value \\
\hline Intercept & 385 & 1495 & $<.0001$ & 394 & 4294 & $<.0001$ & 699 & 6324 & $<.0001$ & -111 & 3567 & $<.0001$ \\
\hline$C$ & -9.68 & 0.032 & .885 & -8.48 & 143 & $<.0001$ & -16.2 & 761 & $<.0001$ & 7.63 & 25.9 & $<.0001$ \\
\hline$T$ & -4.79 & 37.9 & .0003 & -6.46 & 41.6 & $<.0001$ & -11.9 & 421 & $<.0001$ & 2.45 & 90.3 & $<.0001$ \\
\hline$t$ & -1.43 & 0.74 & .4938 & -1.63 & 70.6 & $<.0001$ & -1.26 & 118 & $<.0001$ & -2.71 & 2147 & $<.0001$ \\
\hline$C^{*} C$ & 0.083 & 1006 & $<.0001$ & 0.076 & 849 & $<.0001$ & 0.132 & 2519 & $<.0001$ & -0.078 & 870 & $<.0001$ \\
\hline$T^{*} T$ & 0.036 & 191 & $<.0001$ & 0.086 & 1065 & $<.0001$ & 0.063 & 573 & $<.0001$ & -0.027 & 106 & $<.0001$ \\
\hline$t^{*} t$ & 0.024 & 428 & $<.0001$ & 0.047 & 1669 & $<.0001$ & 0.035 & 932 & $<.0001$ & 0.017 & 202 & $<.0001$ \\
\hline$C^{*} T$ & 0.026 & 55.6 & $<.0001$ & & & & 0.106 & 902 & $<.0001$ & & & \\
\hline$C^{*} t$ & & & & 0.037 & 256 & $<.0001$ & 0.052 & 489 & $<.0001$ & & & \\
\hline$T^{*} t$ & & & & -0.065 & 771 & $<.0001$ & 0.03 & 169 & $<.0001$ & 0.017 & 54.7 & $<.0001$ \\
\hline Lack of fit & & 1.78 & $.997 \mathrm{NS}$ & & 1.94 & .964 & & 0.062 & $.999 \mathrm{NS}$ & & 0.87 & $.776 \mathrm{NS}$ \\
\hline \multicolumn{13}{|c|}{ Statistic analysis for the } \\
\hline R-squared & & 0.981 & & & 0.997 & & & & .999 & & & .999 \\
\hline Adj R-squared & & 0.981 & & & 0.995 & & & & .998 & & & .999 \\
\hline $\mathrm{CV}$ & & 6.66 & & & 3.95 & & & & 2.90 & & & .480 \\
\hline
\end{tabular}

$C, T$, and $t$ are sucrose concentration $\left({ }^{\circ} \mathrm{B}\right)$, temperature $\left({ }^{\circ} \mathrm{C}\right)$, and contact time $(\mathrm{min}) .{ }^{* *}$ Significant within a $99 \%$ confidence interval. ${ }^{*}$ Significant within a $95 \%$ confidence interval. NS: non significant.

\section{Results and Discussions}

3.1. Model Fitting. The experiment results are shown in Tables 1 and 2. The second-order polynomial response surface model (5) was fitted to each of the response variables $(Y)$, and the sum of squares of the sequential models was analyzed. These analyses indicated that adding terms up to quadratic significantly improved the model (data not given). In order to determine the significant effects of process variables on each response, an analysis of variance was the approach used, and the results are shown in Tables 3 and 4 . The ANOVA results indicated that lack of fit was not significant $(P>.05)$ for any of the responses which meant that all models were adequate for describing the influence of process variables on the responses. The coefficient of determination, $R^{2}$, was found to be higher than 0.85 for 


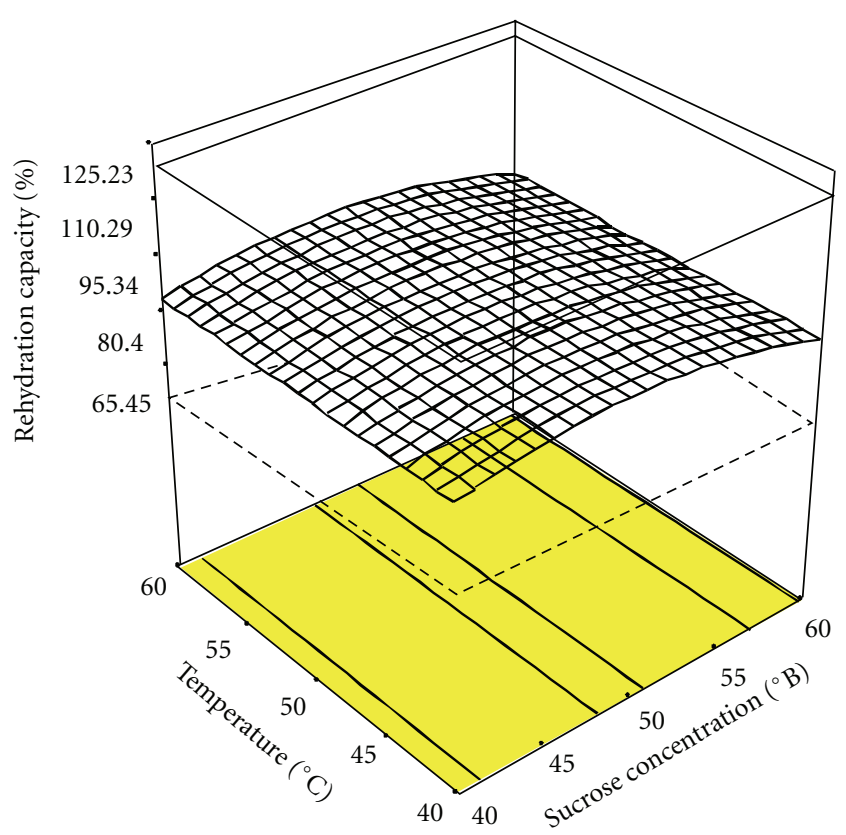

(a)

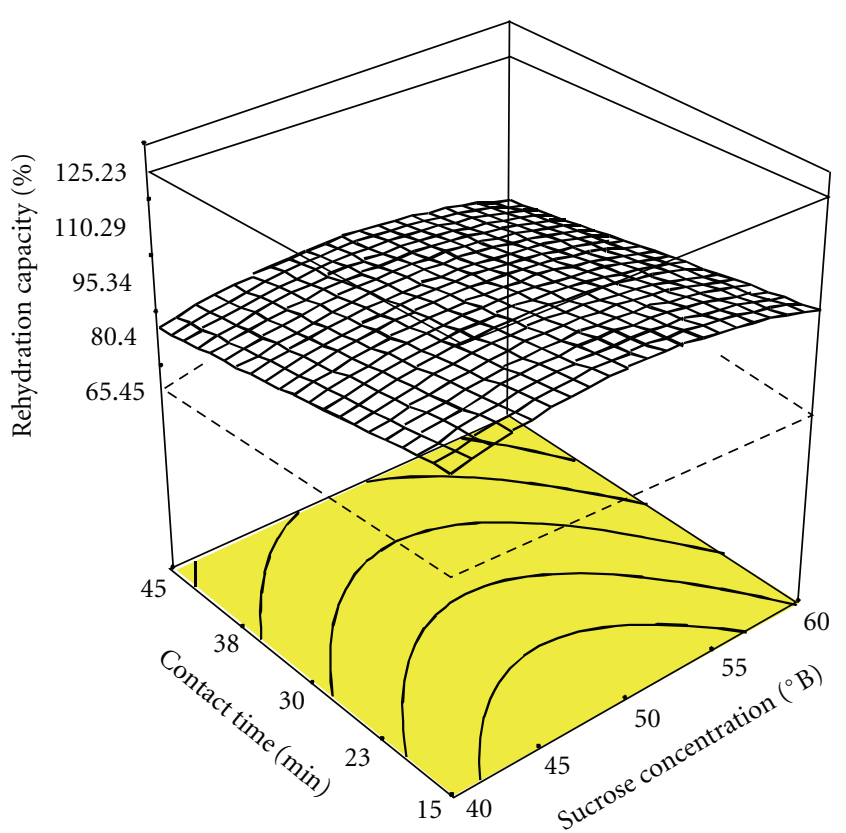

(b)

FIGURE 5: Response surface curves for rehydration capacity (\%): (a) effect of sucrose concentration and temperature at contact time 30 min; (b) effect of sucrose concentration and contact time at temperature $30^{\circ} \mathrm{C}$. The dashed square line is for air-dried sample $(\mathrm{RC}=65.5 \%)$, and the solid square line is for the freeze-dried sample $(\mathrm{RC}=120)$.

all the responses. Moreover, the fact that the coefficient of variation $(\mathrm{CV})$ was less than $10 \%$ indicated that the variation in the mean value was low; therefore, the response models were satisfactorily.

\subsection{Effect of MW Treatment Variables on Color Parameters}

3.2.1. $L^{*}, a^{*}$, and $b^{*}$ Values. $L^{*}$ and $a^{*}$ values (Table 3 ) were significantly $(P<.05)$ affected by linear effects of temperature, and contact time (but not concentration) and all quadratic effects of independent variables, but the interaction effects of sucrose concentration, temperature and contact time were not significant $(P>.05)$. The $b^{*}$ value was significantly $(P<.05)$ affected by linear effects of temperature and contact time, the quadratic effects of concentration and temperature, and the interaction effects of sucrose concentration with temperature and sucrose concentration with contact time. The linear effect of concentration and quadratic effect of time were not significant.

The coefficients of the fitted model for the color responses based on actual values are shown in Table 3. The $L^{*}$ value indicates the lightness of the sample and it has been used as an indicator of fruit browning. The results showed that MWODS-air-dried apples had a higher $L^{*}$ value when compared with $\mathrm{AD}$ apples. The effect of contact time was more significant than sucrose concentration and temperature. Generally, the lightness values increased up to a certain contact time, concentration, and temperature and then decreased. Similar OD effects have been previously observed [16]. MWODS pretreated samples did not discolor as much as the $\mathrm{AD}$ apples and their lightness $\left(L^{*}\right)$ values were close to the $L^{*}$ value of FD samples. Freeze-drying prevents color changes in dried fruit products [1].

The $a^{*}$ value indicates chromaticity on a green $(-)$ to red $(+)$ axis. Increasing $a^{*}$ value has been used as an indicator of fruit browning, and higher $a^{*}$ value shows that the samples are more red. The $a^{*}$ values initially decreased with increasing sucrose concentration, temperature, and contact time; however, at higher levels of these variables, the $a^{*}$ value showed a slightly increasing trend. This might be due to solids accumulation during osmotic pretreatment and possible membrane swelling/plasticizing effect, which might have increased the cell membrane permeability to sucrose molecules $[2,17]$, consequently increasing the color intensity of the products. Comparison of MWODS-air-dried apples with $\mathrm{AD}$ and $\mathrm{FD}$ showed that $\mathrm{AD}$ apples had a higher $a^{*}$ value and were more brown, while FD samples had lower $a^{*}$ value and were very close to the MWODS air-dried apples.

The $b^{*}$ value is an indicator of blue $(-)$ to yellow (+) color. The $b^{*}$ value had a synergistic effect due to the combination of sucrose concentration and temperature; the trends were somewhat similar to that of $L^{*}$ value. The $b^{*}$ value in MWODS-dried samples did not show a major difference from AD and FD apples. Prothon et al. (2001) [9] reported that osmotically pretreated samples did not brown as much as the untreated samples and the value for $b^{*}$ values increased slightly.

3.2.2. $\Delta E$, Chroma, and Hue Angle. $\Delta E$ were significantly $(P<.05)$ affected by linear effects of temperature and contact time, all quadratic effect of independent variables, whereas the interaction effects of sucrose concentration, temperature, 
TABLE 5: Results of optimization by desirability function.

\begin{tabular}{|c|c|c|c|c|c|c|c|c|}
\hline Name & Goal & Limit & Limit & Weight & Weight & Importance & & \\
\hline$C$ & Is in range & 40 & 60 & 1 & 1 & 3 & & \\
\hline$T$ & Is in range & 40 & 60 & 1 & 1 & 3 & & \\
\hline$T$ & Is in range & 15 & 45 & 1 & 1 & 3 & & \\
\hline$L$ & Maximize & 72.02 & 83.55 & 1 & 1 & 3 & & \\
\hline$\Delta E$ & Minimize & 5.93 & 15.72 & 1 & 1 & 3 & & \\
\hline Hardness & Minimize & 3.30 & 29.97 & 1 & 1 & 3 & & \\
\hline $\mathrm{RC}$ & Is in range & 64.78 & 122.26 & 1 & 1 & 3 & & \\
\hline \multicolumn{9}{|l|}{ Solutions } \\
\hline Number & $C$ & $T$ & $t$ & $L$ & $\Delta E$ & Hardness & $\mathrm{RC}$ & Desirability \\
\hline 1 & 49.61 & 51.87 & 33.37 & 82.27 & 6.20 & 7.12 & 88.50 & 0.904 \\
\hline 2 & 49.62 & 51.87 & 33.37 & 82.27 & 6.20 & 7.12 & 88.50 & 0.904 \\
\hline 3 & 49.60 & 51.86 & 33.36 & 82.27 & 6.20 & 7.12 & 88.50 & 0.904 \\
\hline 4 & 49.62 & 51.84 & 33.38 & 82.27 & 6.20 & 7.12 & 88.48 & 0.904 \\
\hline 5 & 49.62 & 51.87 & 33.35 & 82.27 & 6.20 & 7.12 & 88.51 & 0.904 \\
\hline 6 & 49.60 & 51.87 & 33.35 & 82.27 & 6.20 & 7.12 & 88.51 & 0.904 \\
\hline 7 & 49.62 & 51.86 & 33.39 & 82.27 & 6.20 & 7.12 & 88.48 & 0.904 \\
\hline 8 & 49.62 & 51.88 & 33.38 & 82.27 & 6.20 & 7.13 & 88.49 & 0.904 \\
\hline 9 & 49.62 & 51.88 & 33.38 & 82.27 & 6.20 & 7.13 & 88.49 & 0.904 \\
\hline 10 & 49.63 & 51.85 & 33.39 & 82.27 & 6.20 & 7.12 & 88.48 & 0.904 \\
\hline
\end{tabular}

and contact time were not significant $(P>.05)$ (Table 3$)$. The Chroma value was significantly $(P<.05)$ affected by all linear and quadratic and interaction effects of sucrose concentration with temperature and sucrose concentration with contact time. The Hue angle was significantly $(P<.05)$ affected by linear effect of temperature and contact time and all quadratic effects of sucrose concentration, temperature, and contact time, whereas the interaction of independent variables was not significant $(P>.05)$.

$\Delta E$ is the total color difference which obtained as the combined differences in $L^{*}, a^{*}$, and $b^{*}$ values (1) and has been extensively used to present the color variance of foods during processing. Instead of showing the individual effects of $L^{*}, a^{*}$, and $b^{*}$, their combined influence as $\Delta E$ is shown in Figure 1. These were also compared with the untreated AD and FD samples. The results demonstrated a small decreasing effect (but significant) of treatment time and temperature on $\Delta E$ while concentration effect was even smaller. More important is the comparison of MWODS with other drying methods which revealed that $\Delta E$ was much smaller in MWODS apples than in AD, and it was very close to those obtained by FD. Falade et al. (2007) [3] reported the same results during drying watermelon.

Figure 2 presents the effect of sucrose concentration, temperature, and contact time on the Hue angle. Hue angle is the average of red, yellow, and blue. If the value of Hue angle is higher than $90^{\circ}$, this means that the product is less yellow and greener. On the other hand, when the Hue angle value is less than $90^{\circ}$, this means that the product is orangered color [18]. The results revealed again relatively minor influence of process variables on the Hue angle. The trend with Hue angle was opposite to what was observed with $\Delta E$, demonstrating an increasing trend with treatment time and temperature, but again the concentration demonstrates the least effect. The MWODS pretreatment remarkably increased the Hue angle above AD level. Comparison of MWODS-airdried with freeze-dried samples showed that, at some points $\left(60^{\circ} \mathrm{B} / 60^{\circ} \mathrm{C}\right)$, the Hue angle with MWODS was even higher than with FD sample.

Figure 3 presents the effect of MWOD treatment on the Chroma value which is the degree of color saturation and relates to the strength of the color. A greater chroma value represents a more pure and intense color [19]. The Chroma value was more sensitive to the osmotic variables than the other $\Delta E$ and Hue angle. The Chroma values decreased with an increase in treatment time, temperature, and concentration. Moreover, the results showed that values of chroma of MWODS-dried samples under different conditions were close to the ones for FD apples, while they were much different from AD samples. This indicates the stability of the yellow color in apples by the treatment [20].

\subsection{Effect of Process Variables on Mechanical Responses}

3.3.1. Hardness. Texture measurements of MWODS-airdried, $\mathrm{AD}$, and FD apples were carried out through puncture force. The mean values of mechanical responses (hardness, energy and rigidity) in MWODS-air-dried apples can be observed in Table 2 and the model characteristics are in Table 4. Hardness was significantly affected by linear effect of temperature, and all quadratic effects of sucrose concentration, temperature and contact time, and the interaction effects of sucrose concentration with temperature $(P<$ .0001).

Figure 4 shows the effect of the interaction of sucrose concentration with temperature and sucrose concentration 
with contact time on hardness, which is the maximum force in the force-distance curve. It can be observed that the hardness of dried apples is decreased by an increase in the sucrose concentration. Textural properties of fruits are closely linked to cellular structure and pectic composition. MonsalveGonÁLez et al. 1993 [21], observed tissue softening during OD of Red Delicious apple cylinders, which was attributed to pectin solubilization and associated cell separation during soaking. At higher sucrose concentration $>50^{\circ} \mathrm{B}$, the hardness of the samples was increased. This could be due to the blocked pores in the fruit tissue, leading to a thicker cell wall, thereby, increasing the hardness of the samples [9].

Increasing temperature and contact time showed the same results as sucrose concentration. As can be seen in Figure $4(\mathrm{~b})$, contact time $>30 \mathrm{~min}$ favors hardness, moderated by the prevailing osmotic concentration difference between the fruit and the solution results in increasing the hardness of apples. Notable differences in the hardness of the MWODS-air-dried and AD samples can be observed. A great increase in hardness has been observed in AD samples while MWODS-air-dried samples had a lower hardness and were softer than $\mathrm{AD}$ apples $[22,23]$. This could be explained by losing of turgor and ion movement from the cell wall to the surrounding medium $[11,24]$. The hardness of FD samples was lower than from the osmotic treatment due to more porosity in its texture [6]; however, the FD samples were brittle.

3.3.2. Rigidity. All linear and quadratic effects of independent variables and all interaction effect of sucrose concentration with contact time and temperature with contact time on the rigidity were significant $(P<.0001)$ (Table 4$)$. The rigidity of samples in MWODS-air-dried apples was higher than that in untreated ones which is probably due to solids uptake during the osmotic process; in addition, pectic substances at the middle lamella are redistributed during osmotic dehydration which provides support to plant cells and better structural integrity. However, the loss of turgor pressure in untreated dried samples results in reducing the cell's ability to regain its original form [25]. The decrease in rigidity in FD apples means that less distance was required to move through a structure of apple, which was due to the prose structure of FD apples, allowing the probe to move the cells easily. Pereira et al. (2006) [16] reported that sucrose concentration treatment in melons preserved the texture characteristics, avoiding severe softening, and that higher sucrose concentration $\left(60^{\circ}\right.$ Brix sucrose) resulted in increasing the hardness of dried melon.

3.4. Absorbed Energy during the Compression Test. The energy absorbed was significantly $(P<.0001)$ affected by linear, quadratic, and interaction effects of sucrose concentration, temperature, and contact time (Table 4). The energy response of MWODS-air-dried apple was lower than the one of the untreated samples which means that osmotic dehydrated samples were softer. During air-drying, the internal structure of the fruit is deformed resulting in formation of crystalline regions in the amorphous polymers due to crosslinking of polymers; water removal added more rigidity to the external layers; as a result, the energy in $\mathrm{AD}$ samples increased [26]. The outer layers of untreated air-dried apples become rigid, and considerable mechanical strength is thereby acquired [27]. The energy associated with MWODS samples was higher than that with FD ones, because the infusion of sugar inside the fruit resulted in increasing the viscous nature of fruit and decreasing its elasticity [5].

3.5. Effect of Process Variables on Rehydration Capacity. Table 2 gives the mean value of rehydration capacity (RC) for MWODS-air-dried apples. The results given in Table 4 show that all linear and quadratic effects of independent variables and interaction effect of temperature and contact time had a significant impact on rehydration capacity $(P<.0001)$. Figure 5 shows the response surface plot of RC versus two independent variables ((sucrose concentration and temperature) and (sucrose concentration and contact time), respectively). The rehydration capacity generally increased with sucrose concentration and temperature; however at concentration and temperatures beyond their central points, the $\mathrm{RC}$ was reduced demonstrating a slightly convex response surface trend. It might be due to accumulation of sucrose molecules along the surface of cytoplasm resulting in formation of a dense superficial layer, which could have actually decreased the water absorption [1]. Increasing temperature resulted in increasing RC, whereas increasing contact time had a negative effect on RC. Comparing three methods of drying revealed that RC in MWODS-air-dried samples was higher than that in untreated $\mathrm{AD}$ and lower than that in FD samples. This could be the result of the fact that freeze-dried samples are more porous and the cell stricture is more permeable to the absorption of water resulting in a higher RC. Similar results were obtained by Prothon et al. 2001 [9].

3.6. Optimization. The optimal conditions for the MWODSair-dried apples were predicted using the optimization function of the Design Expert software. These are presented in Table 5. The optimum condition for MWODS-air-dried apples was determined to obtain maximum $L^{*}$ value, minimum $\Delta E$, minimum hardness, and maximum rehydration capacity, while sucrose concentration, temperature, and contact time were kept in the ranges $40-60^{\circ} \mathrm{B}, 40-60^{\circ} \mathrm{C}$, and 15 , 45 min respectively. Among the various optimum conditions, the highest value of L: 82.3, hardness: $7.12 \mathrm{~N}$, rehydration capacity: $88.5 \%$, and minimum $\Delta E: 6.2$ were provided by using sucrose concentrations of $50^{\circ} \mathrm{B}$, a temperature of $52^{\circ} \mathrm{C}$, and contact time of $33 \mathrm{~min}$ with the 0.90 desirability. Other constraints can be imposed for the desired optimization such as air-drying time and total time.

\section{Conclusions}

In conclusion, a dehydrated product with less color change and a more rigid and softer structure was obtained by the MWODS-air-dried apples. The MWODS-air-dried samples exhibited higher values for all the color parameters than 
those seen in the untreated air-dried samples and close to $\mathrm{FD}$ apples. Generally, $L^{*}$ and $b^{*}$ values increased in the MWODS-air-dried apples while $a^{*}$ values decreased. Higher color intensity and chroma values were recorded in MWODS-air-dried apples than in the air-dried ones. In addition, the texture of MWODS-air-dried samples was softer than the untreated air-dried ones, while FD apples were more brittle.

\section{Nomenclature}

MWODS: Microwave osmotic dehydration under continuous flow medium spray

AD: $\quad$ Air-dried

FD: $\quad$ Freeze-dried

$L L_{\mathrm{o}}$ : Lightness of sample and standard, respectively (dimensionless)

$a a_{\mathrm{o}}: \quad$ Chromaticity coordinates (red to green) of sample and standard

$b b_{0}$ : Chromaticity coordinates (yellow to blue) of sample and standard

$\Delta E: \quad$ Total color difference.

\section{References}

[1] F. Nsonzi and H. S. Ramaswamy, "Quality evaluation of osmoconvective dried blueberries," Drying Technology, vol. 16, no. 3-5, pp. 705-723, 1998.

[2] E. Azarpazhooh and H. S. Ramaswamy, "Microwave-osmotic dehydration of apples under continuous flow medium spray conditions: comparison with other methods," Drying Technology, vol. 28, no. 1, pp. 49-56, 2010.

[3] K. O. Falade, J. C. Igbeka, and F. A. Ayanwuyi, "Kinetics of mass transfer, and colour changes during osmotic dehydration of watermelon," Journal of Food Engineering, vol. 80, no. 3, pp. 979-985, 2007.

[4] K. O. Falade and J. C. Igbeka, "Osmotic dehydration of tropical fruits and vegetables," Food Reviews International, vol. 23, no. 4, pp. 373-405, 2007.

[5] M. K. Krokida, V. T. Karathanos, and Z. B. Maroulis, "Effect of osmotic dehydration on color and sorption characteristics of apple and banana," Drying Technology, vol. 18, no. 4-5, pp. 937-950, 2000.

[6] T. M. Lin, T. D. Durance T., and C. H. Scaman, "Characterization of vacuum microwave, air and freeze dried carrot slices," Food Research International, vol. 31, no. 2, pp. 111-117, 1998.

[7] S. M. Alzamora, L. N. Gerschenson, S. L. Vidales, and A. Nieto, "Structural changes in the minimal processing of fruits: some effects of blanching and sugar impregnation," in Food Engineering 2000, pp. 117-139, Chapman \& Hall, New York, NY, USA, 1996.

[8] C. Contreras, M. E. Martín-Esparza, N. Martínez-Navarrete, and A. Chiralt, "Influence of osmotic pre-treatment and microwave application on properties of air dried strawberry related to structural changes," European Food Research and Technology, vol. 224, no. 4, pp. 499-504, 2007.

[9] F. Prothon, L. M. Ahrné, T. Funebo, S. Kidman, M. Langton, and I. Sjöholm, "Effects of combined osmotic and microwave dehydration of apple on texture, microstructure and rehydration characteristics," Food Science and Technology, vol. 34, no. 2, pp. 95-101, 2001.
[10] R. Moreira, F. Chenlo, L. Chaguri, and C. Fernandes, "Water absorption, texture, and color kinetics of air-dried chestnuts during rehydration," Journal of Food Engineering, vol. 86, no. 4, pp. 584-594, 2008.

[11] P. P. Lewicki, "Effect of pre-drying treatment, drying and rehydration on plant tissue properties: a review," International Journal of Food Properties, vol. 1, no. 1, pp. 1-22, 1998.

[12] F. Nsonzi and H. S. Ramaswamy, "Osmotic dehydration kinetics of blueberries," Drying Technology, vol. 16, no. 3-5, pp. 725741, 1998.

[13] N. Maftoonazad and H. S. Ramaswamy, "Effect of pectinbased coating on the kinetics of quality change associated with stored avocados," Journal of Food Processing and Preservation, vol. 32, no. 4, pp. 621-643, 2008.

[14] A. Levi, N. Ben Shalom, D. Plat, and D. Reid, "Effect of blanching and drying on pectin constitutents and related characteristics of dehydrated peaches," Journal of Food Science, vol. 53, pp. 1187-1190, 1988.

[15] R. H. Myers and D. C. Montgomery, Response Surface Methodology: Process and Product Optimization Using Designed Experiments, John Wiley \& Sons, New York, NY, USA, 2nd edition, 2002.

[16] L. M. Pereira, C. C. Ferrari, S. D. S. Mastrantonio, A. C. C. Rodrigues, and M. D. Hubinger, "Kinetic aspects, texture, and color evaluation of some tropical fruits during osmotic dehydration," Drying Technology, vol. 24, no. 4, pp. 475-484, 2006.

[17] H. Li and H. S. Ramaswamy, "Osmotic dehydration of apple cylinders-III. Continuous medium flow microwave heating conditions," Drying Technology, vol. 24, no. 5, pp. 643-651, 2006.

[18] K. N. Waliszewski, J. L. Delgado, and M. A. Garcia, "Equilibrium concentration and water and sucrose diffusivity in osmotic dehydration of pineapple slabs," Drying Technology, vol. 20, no. 2, pp. 527-538, 2002.

[19] Y. Pomeranz and C. Meloan, Food Analysis: Theory and Practice, Springer, 2000.

[20] J. Moreno, A. Chiralt, I. Escriche, and J. A. Serra, "Effect of blanching/osmotic dehydration combined methods on quality and stability of minimally processed strawberries," Food Research International, vol. 33, no. 7, pp. 609-616, 2000.

[21] A. Monsalve-GonÁLez, B.-C. Gustavo, and C. Ralph, "Mass transfer and textural changes during processing of apples by combined methods," Journal of Food Science, vol. 58, pp. 11181124, 1993.

[22] E. Maltini, D. Torreggiani, B. R. Brovetto, and G. Bertolo, "Functional properties of reduced moisture fruits as ingredients in food systems," Food Research International, vol. 26, no. 6, pp. 413-419, 1993.

[23] I. G. Mandala, E. F. Anagnostaras, and C. K. Oikonomou, "Influence of osmotic dehydration conditions on apple airdrying kinetics and their quality characteristics," Journal of Food Engineering, vol. 69, no. 3, pp. 307-316, 2005.

[24] M. L. Castelló, P. J. Fito, and A. Chiralt, "Changes in respiration rate and physical properties of strawberries due to osmotic dehydration and storage," Journal of Food Engineering, vol. 97, no. 1, pp. 64-71, 2010.

[25] M. M. Khin, W. Zhou, and S. Y. Yeo, "Mass transfer in the osmotic dehydration of coated apple cubes by using maltodextrin as the coating material and their textural properties," Journal of Food Engineering, vol. 81, no. 3, pp. 514-522, 2007. 
[26] P. P. Lewicki and E. Jakubczyk, "Effect of hot air temperature on mechanical properties of dried apples," Journal of Food Engineering, vol. 64, no. 3, pp. 307-314, 2004.

[27] P. P. Lewicki, D. Witrowa-Rajchert, and J. Mariak, "Changes of structure during rehydration of dried apples," Journal of Food Engineering, vol. 32, no. 4, pp. 347-350, 1997. 

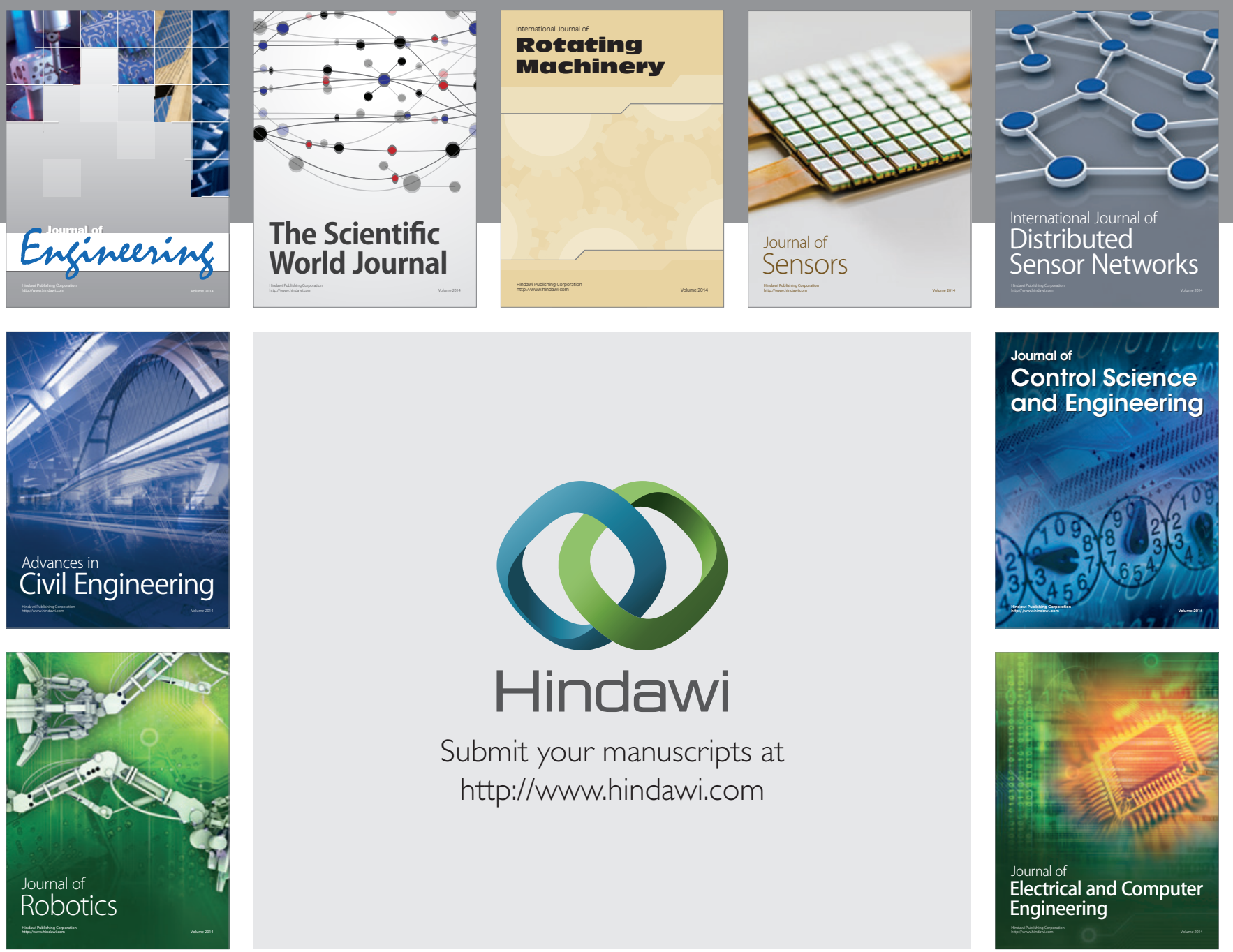

Submit your manuscripts at

http://www.hindawi.com
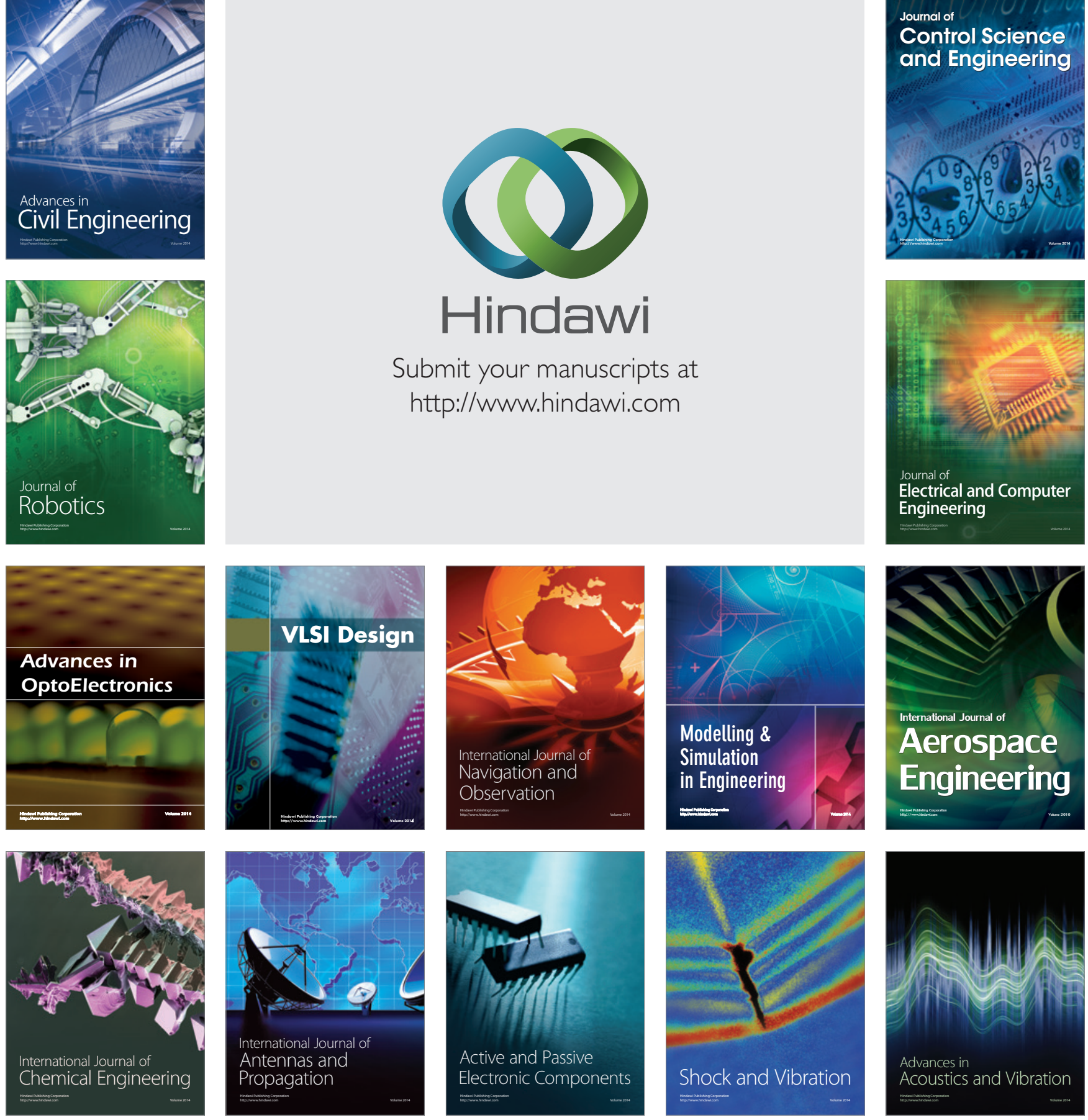